\title{
Durian Seed Causing Small Bowel Obstruction
}

\author{
V.G. Shelat J. Tan \\ Department of Surgery, Tan Tock Seng Hospital, Singapore, Singapore
}

A 60 -year-old male was admitted with complaints of abdominal pain and distension of 2 days duration. $\mathrm{He}$ gave a history of accidentally swallowing a large durian seed 3 days earlier. There was no past history of abdominal surgery or dental problems. On examination he was afebrile and dehydrated. His abdomen was distended but soft and had mild generalized tenderness. Abdominal Xray revealed air fluid levels suggestive of small bowel obstruction (SBO). CT scan was done, and it suggested a foreign body in the terminal ileum with proximal small bowel dilatation and collapsed distal colon (fig. 1). He underwent urgent exploratory laparotomy. Intraoperatively a $3.5 \times 2.5 \mathrm{~cm}$ durian seed was found impacted at the terminal ileum. Enterotomy was performed proximally, and the seed was manipulated out. The bowel was healthy, and primary repair of enterotomy site was performed.

A foreign body is an uncommon cause of $\mathrm{SBO}$, and a durian seed causing SBO is unreported to date. Nonoperative treatment is recommended in selected cases of postoperative adhesions and in cases where strangulation is ruled out. In complete mechanical SBO, early surgery is advocated to avoid strangulation and its disastrous consequences.

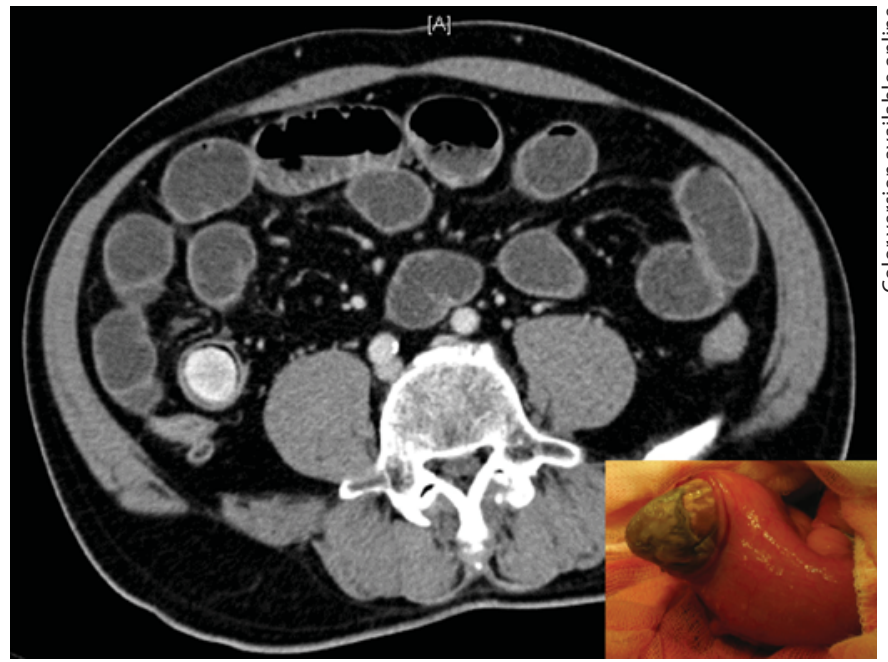

Fig. 1. CT scan showing foreign body obstruction at the terminal ileum with small bowel dilatation. Inset showing the durian seed being removed by enterotomy.

\section{KARGER}

Fax +41613061234 E-Mail karger@karger.ch www.karger.com
Dr. Vishalkumar G. Shelat

Department of Surgery, Tan Tock Seng Hospita

11, Jalan Tan Tock Seng

Singapore 308433 (Singapore)

Tel. +65 6357 7807, Fax +65 6357 7809, E-Mail vgshelat@rediffmail.com 